\title{
Correction notice to: Early results of total hip arthroplasty using dual-mobility cup in patients with osteonecrosis of the femoral head
}

SICOT-J 2018, 4, 4, https://doi.org/10.1051/sicotj/2018001

Chahine Assi $^{1}$, Nadim Kheir ${ }^{1}$, Camille Samaha ${ }^{1,2}$, Pascal Kouyoumdjian ${ }^{3}$, and Kaissar Yammine ${ }^{1,4,{ }^{*}}$

${ }^{1}$ Department of Orthopedic Surgery, Lebanese American University-Rizk Hospital, Beirut, Lebanon

${ }^{2}$ Department of Orthopedic Surgery, Middle East Institute of Health, Bsalim, Lebanon

${ }^{3}$ Department of orthopedic Surgery, Centre Hospitalier Universitaire de Nîmes, Nîmes, France

${ }^{4}$ Center for Evidence-based Anatomy, Sports \& Orthopedic Research, Jdeideh, Lebanon

Received 28 May 2018, Accepted 28 May 2018, Published online 3 September 2018

The name of the third author "Pascal Kouyoumjian" has been corrected to "Pascal Kouyoumdjian". The publisher apologizes for any inconveniences.

\footnotetext{
*Corresponding author: cesaryam@gmail.com
} 